\title{
DONA VERA: MULHER ARRETADA DA GOTA SERENA
}

Eúde Do Amor Cornélio ${ }^{1}$

Monica Cristina Rovaris Machado ${ }^{1}$

Darlane Amorim Vieira ${ }^{1}$

Lucas Gabriel Bezerra Lima ${ }^{1}$

\footnotetext{
${ }^{1}$ Universidade Federal de Sergipe
} 


\section{DONA VERA: MULHER ARRETADA DA GOTA SERENA}

Resumo: Este caso de ensino relata a trajetória de D. Vera, uma empreendedora no estado de Sergipe, e de seu empreendimento, situado na área turística da cidade. Trata-se de uma história real de uma mulher que, diante da necessidade, viu uma oportunidade de negócio na feira de turismo da cidade. Após algumas experiências de trabalho que precederam a abertura do negócio, enfrentou uma séria crise financeira e encontrou-se diante de uma situação desafiadora. O que fazer? Ela precisava sobreviver! A oportunidade de empreender numa barraquinha, ainda que com dificuldades, saltou aos olhos, mas a convivência com os outros feirantes e o sonho de ter um negócio maior foram decisivos na busca do seu sonho. Mesmo depois dos percalços, ela alcançou seu objetivo e hoje é uma empreendedora de sucesso. No presente caso, é possível identificar aspectos que remetem ao perfil empreendedor e suas características e ao processo da tomada de decisão.

Palavras-chave: Características empreendedoras. Comportamento empreendedor. Tomada de decisão. Administração Estratégica.

\section{$1 \quad$ Quando deu fé, emburacou no trabalho}

Vera começou a trabalhar muito cedo, desde os 14 anos de idade. Na década de 80, foi admitida em uma empresa de cosméticos, onde iniciou suas atividades abastecendo as gôndolas como promotora de vendas, depois passou a ser demonstradora, função que realizou após um treinamento capilar. Dentro da empresa trabalhava com técnicas relacionadas a cabelo: coloração, descoloração, percentual de cobertura, colorimetria. Era uma gama imensa de aprendizado. Nesse período, ela conheceu Nestor, seu atual esposo. Quando isso aconteceu, era separada e tinha dois filhos do primeiro casamento. Devido a projetos pessoais, saiu da empresa no ano de 2007.

Após sair da empresa de cosméticos, D. Vera começou a trabalhar na área de turismo com seu esposo Nestor, por acreditar ser uma área de expansão na economia, chegando a cursar alguns semestres do curso superior em Turismo, entretanto, este curso não atendeu às suas expectativas. $\mathrm{Na}$ operadora de turismo, seu trabalho era intenso, pois vendiam passagens e pacotes turísticos, já que atendiam às agências do estado e, ainda, tinham uma parceria com 25 companhias aéreas. Após 5 anos, depois de iniciado o empreendimento, a agência decidiu inovar, entrando no segmento de cartões de crédito. Mas como nem tudo são flores, os cartões foram clonados e ficaram com um prejuízo de 280 mil reais, sem poder pagar na rua. E, com isso, veio a falência. O que fazer agora?

\section{Sem arrudeio! Eu vou pelejar!}

Diante da crise que assolou D. Vera, numa tarde de sábado ela estava perdida em seus pensamentos e começou a observar seu vizinho, que era um velho conhecido da empresa Varig e viera do Rio de Janeiro para Aracaju em busca de novos ares. Eles conversavam com frequência, e ele sempre falava que, quando se aposentasse, iria viajar muito, não queria nem saber de trabalho. Ele se aposentou e fez apenas uma viagem. Confessou a Vera que esse novo estilo de vida não lhe agradou, principalmente, porque ficar em casa o deixou entediado. Então, começou a frequentar o aeromodelismo, um antigo hobby, e sua esposa viu a oportunidade de 
vender bolos e salgados. Todos os sábados preparavam os quitutes, colocavam na mala do carro e vendiam para o pessoal dos "aviõezinhos". Nesse dia, D. Vera o viu passando com a aquela parafernália e perguntou curiosa:

- Alberto, pra onde você vai?

- Ah, eu tô vendendo bolo porque ninguém merece ficar dentro de casa, disse ele.

Nesse momento, D. Vera viu uma possibilidade de empreender. Com a crise na agência, ela já estava de olho para comprar uma barraquinha na feira de turismo na capital do estado de Sergipe. Ela percebeu que não havia mais condições de continuar com a empresa por causa da situação em que se envolveram, pois não tinham capital de giro, então decidiu:

- Vamos fechar a agência e começar um novo empreendimento, disse ela para Nestor.

Com muitos conhecidos na cidade, D. Vera procurou o Sr. Raimundo, pois estava buscando outras oportunidades de negócios e viu, na Feirinha de turismo, uma oportunidade para atender a sua necessidade de sobrevivência. Marcou uma reunião com ele e, no dia e hora marcados, estava lá.

Ela perguntou para ele:

- Obrigada por o Sr. me receber, então foi direta: Raimundo, me diga, como funciona a feirinha? Posso trabalhar lá?

Ele respondeu:

- Vera, lá tem duas barracas, a da macaxeira e a do Seu João do Pastel.

Ela foi visitar a feira, já para observar as barracas indicadas pelo Sr. Raimundo. Começou a andar e viu que Sr. João era uma pessoa muito simples de conhecimento e estava machucado, por isso, não conseguia mais trabalhar na sua barraca. Para atender aos clientes, ele colocou uns meninos para trabalhar e "passar a cana" com ele.

Como já era conhecida do casal, D. Vera perguntou como estavam as vendas, foi quando a esposa dele, D. Maria, falou:

- D. Vera, quanto mais eu faço pastel e vendo cana, menos dinheiro eu tenho, reclamou ela.

D. Vera pensou: "tem alguma coisa errada..."

Foi então que ela começou a frequentar a feirinha com assiduidade, antes e depois de ir para a faculdade. Nessas idas e vindas, ela observava o movimento, os dias com maior frequência, o tipo de cliente, entre outros aspectos. Foram 90 dias fazendo esse acompanhamento. Após esse estudo, ela preparou a documentação para apresentar à pessoa que era responsável pela feira, marcou um horário e foi. Muito animada, ela chegou ao local e entregou a documentação. O responsável pegou o envelope, examinou rapidamente os papeis, olhou para ela e disse de maneira bastante direta:

- Você não tem perfil para feira, disse ele. Ela não acreditou no que ouviu, e perguntou:

- Como assim eu não tenho perfil? Eu preciso trabalhar, tenho filho para criar.... O responsável sem cerimônias lhe disse:

- Não, aqui é tudo ex-prostituta, ex-drogado, ex-ambulante. Você vai fazer o que aqui? Você não tem cara!

Com indignação ela pergunta:

- Mas para trabalhar precisa ter cara? Eu preciso de uma oportunidade de trabalho, disse ela de forma enfática.

Diante da situação, o responsável não quis pegar o currículo de D. Vera. 
Indignada, no dia seguinte marcou uma reunião e procurou o responsável pela área na Prefeitura, pois era seu conhecido na época que trabalhava no comércio da cidade, o Sr. Raimundo. E dirigiu-se para a Companhia de Assuntos Municipais, que cuidava da ferinha.

Fez-se anunciar junto à secretaria e entrou na sala do Sr. Raimundo, e de forma bem objetiva, disse:

- Oi Raimundo, boa tarde, estou indignada, você está sabendo da minha situação, minha empresa foi vítima de um golpe e não tenho como continuar meu negócio, estou em busca de alternativas de trabalho, disse ela.

- Sim, estou sabendo, e como posso te ajudar? Perguntou Raimundo.

- Olha, o Seu João e a D. Maria têm uma barraca de pastel lá na feirinha da Orla e estão com problemas, trabalham muito e não veem o dinheiro entrar, estão querendo vender. Tentei entregar meu currículo para a compra do espaço, mas me disseram que eu não tinha perfil para trabalhar lá, fiquei triste, disse ela, já estou com tantos problemas, preciso sustentar minha família...

- Deixa comigo, disse ele.

Raimundo pegou o telefone e ligou para Pedro:

- Oi Pedro, aqui é o Raimundo, boa tarde. Pedro responde:

- Oi Seu Raimundo, boa tarde, em que posso ajudar?

- Olha, eu estou aqui com a D. Vera e ela me disse que tem interesse em comprar uma barraca, a do Sr. João, mas não quiseram nem aceitar a proposta dela, o que aconteceu? Temos que ajudar o Sr. João, ele não está conseguindo trabalhar...

- Olha, eu não sei o que está acontecendo com ela, mas se o Sr. João disse que aceita o negócio com ela, eu também aceito, diga para ela me procurar aqui na feira, disse ele.

E foi assim que Vera começou a trabalhar na feira de turismo da capital de Sergipe.

\section{Se avexe não: a volta por riba}

D. Vera inicia seu empreendimento com uma barraquinha na feirinha de turismo, medindo 3 x $3 \mathrm{~m}$. Para iniciar, só tinham dinheiro para comprar a barraca, mas a luta da empreendedora e da sua família não para por aí. Com a venda dos produtos na feira de uma noite, compravam os alimentos pela manhã, faziam os pastéis e as compras necessárias, para à noite retornarem para a feira e, assim, foram crescendo dentro do espaço comprado.

Quando encontravam algum conhecido ou faziam alguma visita, as pessoas perguntavam:

- Vai fechar a agência?

- Já fechamos! Estamos lá na feirinha, venha nos visitar, a barraca dos pastéis... dizia

ela.

E assim foram trabalhando por longos 3 anos... e o espaço já estava pequeno... Pensavam em ampliar, mas como? Daí os problemas na feira começaram a surgir...

D. Vera já tinha vontade de fazer a casinha de pastel se tornar uma realidade e, por conta disso, saía toda noite de carro e ia até o final da Orla procurando um espaço para montar seu negócio e sair da feirinha, num espaço só seu.

Entretanto, nessa sua jornada, só encontrava empreendimentos na faixa de 200 a 250 mil para vender, e para alugar, estava em torno de 7 a 8 mil, mas eles não tinham dinheiro, tinham acabado de "quebrar", mas a persistência de D. Vera fez com que ela não desistisse e continuou procurando.

Antes de eles trabalharem na feira, faziam parte de um grupo de motociclistas, daquelas que passeavam pelas ruas, cujos membros, alguns deles, trabalhavam nos bancos da cidade. 
Um deles, percebendo o crescimento da barraca na feirinha, perguntou a D. Vera: - A senhora não tem interesse num ponto melhor, já que está com a clientela desse grande porte na feirinha? Perguntou Carlos.

D. Vera, espantada, responde:

- Tenho sim, só que não tenho o dinheiro. Eu cheguei a ver algo aqui na avenida, mas está tudo muito caro, disse ela.

- A senhora tem coragem de construir? Perguntou Carlos.

- Tenho, disse ela, meu problema é que não tenho o dinheiro e nem o local.

- E se o banco tiver? Falou Carlos. Prontamente, Vera respondeu:

- Eu quero!!!!

E aí começou a jornada pelo espaço que ela tanto desejava.... Após a aprovação dos projetos e do plano de negócios, D. Vera fechou parceria com o Sr. Carlos para o início das obras de seu novo empreendimento. Conversaram com o pessoal do terreno e fizeram o contrato de locação. Compraram material de construção, organizaram o terreno para o recebimento das mercadorias e iniciaram a obra usando seu cheque especial e sua capacidade empreendedora. Todavia, mais uma vez, Vera teve um prejuízo. Depois de aprovado o projeto no banco, a construtora responsável pela obra desaparece com o dinheiro do empréstimo, e Vera chorou dia e noite!

\section{Mas hômi, será que dô vencimento?}

Mas sua capacidade de recuperação surpreendeu a todos, recebeu ajuda de amigos e, finalmente, conseguiu terminar a obra. Vera abriu o espaço nas condições que foram possíveis, apesar do desejo em fazer um evento e chamar todos que a ajudaram a realizar seu sonho de um espaço novo. Como não tinha o dinheiro necessário, resolveu que abriria do jeito que estava. Lembra-se, de forma saudosa, de que a primeira cliente que atenderam foi uma professora de Goiânia, que estava a trabalho na cidade.

Ela entrou e disse:

- Nossa, está tudo tão novinho, tem quanto tempo essa casa? Pergunta ela. Vera responde:

- Um dia, hoje.

- Eu sou a primeira? Perguntou a professora.

- É! Responde Vera.

E com o passar do tempo, os clientes que frequentavam a feirinha foram migrando para o novo local, e perguntavam:

- Nossa, o pastel veio pra cá! O pastel veio pra cá! E na Feira perguntavam:

- D. Vera, a casa do pastel é da senhora?

O movimento na avenida estava bom, e o sucesso foi grande. Durante algum tempo, eles ainda tentaram conciliar os dois espaços. No entanto, o clima na feira estava ficando complicado. Devido à expansão dos negócios de D. Vera, seus concorrentes começaram a implicar e boicotá-la administrativamente, até que um dia, a direção da feira a chamou e aplicou uma suspensão de 15 dias. Como se não bastasse, quando Nestor foi abrir a barraquinha, após o período suspenso, aconteceu uma situação desagradável. Era noite de domingo, e as pessoas depois da missa costumavam passar na feira para comer pastel. A noite promete... pensou Nestor.

Mas como o movimento estava muito grande e os pasteis estavam demorando para ficarem prontos, uma cliente perguntou:

- Meu pastel vai sair agora? Disse ela... 
- Não, o da senhora é o $3^{\circ}$ da fila, respondeu o atendente.

De forma surpreendente, ela jogou para o alto todas as comandas e ninguém mais sabia a sequência dos pedidos, foi o caos. Nestor pediu desculpas aos clientes e fechou a barraca de pastel da feira.

Então D. Vera perguntou para Nestor:

- E agora, o que vamos fazer??? Disse ela chorando, com pesar, por tudo o que havia acontecido naquela noite. Vamos continuar aqui e na Orla, ou vamos fechar de vez a barraca?

\section{REFERÊNCIAS}

Sebrae. (Outubro/2017). Revista Pequenas Empresas e Grandes Negócios. Recuperado em 28 de junho de 2019, em

https://revistapegn.globo.com/Negocios/noticia/2017/10/pastelaria-de-aracaju-inova-e- $\underline{\text { se- }}$ torna-referencia-para-moradores-e-turistas.html

Calheiros, C. Dicionário de Nordestinês. Recuperado em 09 de julho de 2019, de https://www.terra.com.br/diversao/dicionario-denordestines,f2bd421a2df4a310VgnCLD200000bbcceb0aRCRD.html

Albuquerque, G. Lista de palavras e expressões nordestinas. Recuperado em 09 de julho de 2019 de http://culturanordestina.blogspot.com/2007/11/dicionario-nordestino.html?m=1 


\section{Sinopse}

Este caso de ensino relata a trajetória de D. Vera, Sr. Nestor e da sua pastelaria, situada na orla de Aracaju - SE. Trata-se de uma história real de uma empreendedora de sucesso, muito conhecida na cidade, que, diante da dificuldade, após seu esposo entrar em colapso numa agência de viagens e, por necessidade de sobrevivência, viu uma oportunidade de negócio na venda de pasteis numa feira da orla da cidade. Até chegar ao sucesso, D. Vera teve toda uma trajetória descrita no caso de ensino que, por muitas vezes, foi abalada em função de equívocos, externalidades e estratégias malsucedidas. No presente caso, é possível identificar aspectos que remetem ao perfil empreendedor e suas características e ao processo da tomada de decisão.

\section{Objetivos Didáticos}

O caso foi desenvolvido com dois principais objetivos pedagógicos:

- Proporcionar ao aluno a vivência de uma situação na qual possa identificar características empreendedoras necessárias ao desenvolvimento do processo empreendedor;

- Promover a discussão sobre comportamento empreendedor na tomada de decisão.

\section{Fontes e Métodos de Coleta dos Dados}

Os dados para construção do caso foram obtidos por meio de entrevistas semiestruturadas com a proprietária do empreendimento. Mesmo com a obtenção da autorização para divulgar os nomes do empreendimento e da própria empresária, optou-se por manter nomes fictícios para os personagens, a fim de preservar suas identidades. Também foram realizadas análises de documentos disponibilizados pela proprietária, além de reportagens sobre o negócio, disponíveis em páginas da internet de domínio público.

\section{Relações com os objetivos de um curso ou disciplina}

No presente caso de ensino, é possível identificar um contexto de crise financeira e consequente falência anterior ao negócio. Retrata diversas características empreendedoras a partir da análise da trajetória de Vera e seu marido, e expõe, em seu contexto, fatos que viabilizam a discussão do desenvolvimento do processo empreendedor. Fortemente sugerido para cursos de graduação em Administração e áreas afins que envolvam aspectos ligados ao empreendedorismo e ao planejamento de micro e pequenas empresas.

É importante ressaltar que o presente caso de ensino não se restringe apenas às abordagens aqui propostas, pois pode e deve ser adequado, conforme a percepção do professor, tendo em vista o objetivo da disciplina.

\section{Disciplinas sugeridas para uso do caso}

As disciplinas que podem utilizar o presente caso de ensino são: Empreendedorismo, Administração Estratégica de Empresas e Gestão de Pequenos Negócios. 


\section{Fundamentação do Caso de Ensino}

O presente caso de ensino traz a realidade do processo de abertura de um novo empreendimento, que nasceu graças às características específicas de uma empreendedora e que, após o seu desenvolvimento, precisou passar pela tomada de decisão, etapa necessária para evolução da empresa.

Desde muito nova, a empreendedora se mostra disposta ao trabalho, e aventura-se na empresa de cosméticos, depois na empresa de viagens do marido até que resolve empreender e, para isso, conta com características empreendedoras presentes em seu comportamento.

Intimamente ligado ao contexto apresentado, Schumpeter (1939) assegura que o empreendedor é aquele que destrói a ordem econômica existente pela introdução de novos produtos e serviços, pela criação de novas formas de organização ou pela exploração de novos recursos e materiais.

Ainda relacionado ao conceito supramencionado sobre empreendedor, pode-se destacar a afirmação de Dolabela (1999) de que as características empreendedoras podem ser adquiridas e desenvolvidas, além de diversificar-se, a depender do ramo de atuação do empreendedor. Durante o processo de criação e condução da empresa deste caso de ensino, podemos identificar e aplicar essas características empreendedoras, das quais listamos 10 (dez), a seguir especificadas:

1 - Busca oportunidades e toma a iniciativa: o empreendedor faz o que deve ser feito antes de ser solicitado ou forçado, age para expandir o negócio, aproveita as oportunidades novas para começar um negócio;

2- Corre riscos calculados: avalia as alternativas, age para controlar os resultados, toma riscos moderados;

3 - Exige qualidade e eficiência: age de maneira a realizar ações, desenvolve procedimentos para assegurar que o trabalho seja executado a tempo e que atenda aos padrões de qualidade; 4 - É persistente: o empreendedor age diante de um obstáculo significativo, assume responsabilidade pessoal pelo desempenho necessário para atingir metas e objetivos;

5 - É comprometido: faz sacrifício pessoal para completar as metas que foram determinadas, se esmera em manter os clientes satisfeitos e coloca em primeiro lugar a boa vontade a longo prazo, acima do curto prazo;

6 - Busca de informações: está sempre buscando novos métodos, novas informações para aprimorar o serviço;

7 - Estabelecimento de metas: o empreendedor estabelece metas e objetivos que são desafiantes;

8 - Planejamento e monitoramento sistemático: planeja dividindo tarefas de grande porte em subtarefas com prazos definidos, constantemente revisa seus planos levando em conta os resultados obtidos e as mudanças circunstanciais, utiliza registros financeiros para tomar decisões;

9 - Persuasão e rede de contatos: o empreendedor utiliza estratégias para influenciar ou persuadir pessoas. Trabalha com pessoas-chave, age para desenvolver e manter relações comerciais;

10 - Independência e autoconfiança: o empreendedor busca autonomia em relação às normas e controle de terceiros, mantém seu ponto de vista, expressa confiança na sua própria 
capacidade de enfrentar um desafio.

Mas, afinal, qual o impacto dessas características no comportamento empreendedor?

Segundo Bressan \& Toledo (2013), as características pessoais do tomador de decisões influenciam diretamente o diagnóstico, as escolhas e a direção estratégica da empresa. Os empreendedores não percebem menos riscos, mas, em vez disso, usam mais valores pessoais para enquadrar os riscos do empreendimento. Eles também são mais confiantes em sua capacidade de influenciar o desenvolvimento do empreendimento no futuro (SAES; MARTINS; SCHNAIDER, 2013). Nesse sentido, a percepção, a organização e o uso das informações parecem ser críticos na tomada de decisão estratégica, e podem servir de base para a análise do processo decisório à luz da influência das características pessoais (BRESSAN; TOLEDO, 2013).

Após a abertura do empreendimento na Orla, D. Vera e Sr. Nestor se viram diante de um dilema: continuar ou não com a barraca na feira. Os desgastes com os vizinhos estavam aumentando e, consequentemente, os aborrecimentos. Diante de toda a situação, eles precisariam tomar a decisão de fechar ou manter o empreendimento, local onde começou a trajetória do casal no ramo da pastelaria.

Nesse sentindo, Préve; Moritz e Pereira (2010) salientam que os processos de tomadas de decisão são constantes no dia a dia organizacional e, a todo instante, as pessoas estão sendo colocadas em uma situação em que é necessário analisar, pesquisar, optar e agir frente às poucas ou às muitas opções que lhes são fornecidas para decidir. Bressan \& Toledo (2013) complementam que as escolhas estratégicas e o processo de tomada de decisão são atribuições essenciais do empreendedor; mesmo que ele delegue autoridade para outras pessoas, as decisões estratégicas continuarão sob sua responsabilidade direta. Nesse caso específico, a decisão caberia à D. Vera e ao Nestor, proprietários do empreendimento. Os autores ressaltam que, em relação ao processo decisório, espera-se que o empreendedor, ao se defrontar com a necessidade de tomar uma decisão, assuma uma orientação racional. Visto que, ao empreender, o escopo da decisão torna-se mais restrito, pois a margem para erros diminui, uma vez que decisões equivocadas podem colocar o empreendimento em risco. Além do mais, nessas circunstâncias, a decisão e suas consequências recairão sobre o próprio empreendedor (BRESSAN; TOLEDO, 2013). Para Préve; Moritz e Pereira (2010), a decisão é um julgamento, uma escolha feita entre alternativas que incluem todos os questionamentos: "o que", "quando", "quem", "por que" e "como", que aparecem nos processos de decisão.

Com o intuito de evitar problemas futuros, os administradores devem se basear em decisões cuidadosamente formuladas e rapidamente implementadas. Desse modo, D. Vera e Nestor deveriam analisar muito bem sobre a decisão a ser tomada, com muita cautela, visto que a tomada de decisão, frequentemente, causa um impacto que vai muito além do resultado imediato. Na realidade, as decisões tomadas hoje se direcionam muito mais ao futuro, que é fruto das idealizações nas quais as decisões são baseadas (PRÉVE; MORITZ; PEREIRA, 2010).

De acordo com Simon (1970), a decisão é um processo de análise e de escolha entre várias alternativas disponíveis do curso de ação que uma pessoa deverá seguir. Ele aponta seis elementos clássicos na tomada de decisão:

- Tomador de decisão: é a pessoa que faz uma escolha ou opção entre várias 
alternativas de ação;

- Objetivos: que o tomador de decisão pretende alcançar com suas ações;

- Preferências: critérios que o tomador de decisão usa para fazer sua escolha;

- Estratégia: o curso da ação que o tomador de decisão escolhe para atingir os objetivos, dependendo dos recursos que venha a dispor;

- Situação: aspectos do ambiente que envolvem o tomador de decisão, muitos dos quais se encontram fora do seu controle, do seu conhecimento ou da sua compreensão e que afetam sua escolha;

- Resultado: é a consequência ou a resultante de uma dada estratégia de decisão.

\section{Possíveis tarefas a propor aos alunos}

Aqui estão algumas questões que devem direcionar a reflexão em sala de aula para que

se chegue a um denominador comum, no que se refere aos objetivos da aula, expostos anteriormente.

Sabemos que as características empreendedoras e a tomada de decisão da empreendedora podem ser facilmente aplicadas ao presente caso de ensino, desde que bem conduzidas, a partir dos seguintes questionamentos:

\section{1- Analise o seguinte fato do caso de ensino:}

Foi então que ela começou a frequentar a feirinha com assiduidade, antes e depois de ir para a faculdade. Nessas idas e vindas, ela observava o movimento, os dias com maior frequência, o tipo de cliente, entre outros aspectos. Foram 90 dias fazendo esse acompanhamento. Após esse estudo, ela preparou a documentação para apresentar à pessoa que era responsável pela feira, marcou um horário e foi. Muito animada, ela chegou ao local e entregou a documentação. O responsável pegou o envelope, examinou rapidamente os papeis, olhou para ela e disse de maneira bastante direta:

- Você não tem perfil para feira, disse ele.

Ela não acreditou no que ouviu, e

perguntou:

- Como assim eu não tenho perfil? Eu preciso trabalhar, tenho filho para

criar.... O responsável sem cerimônias lhe disse:

- Não, aqui é tudo ex-prostituta, ex-drogado, ex-ambulante. Você vai fazer o que aqui? Você não tem cara!

Com indignação ela pergunta:

- Mas para trabalhar precisa ter cara? Eu preciso de uma oportunidade de trabalho, disse ela de forma enfática.

Quais características empreendedoras podemos destacar nesse trecho do caso de ensino? Elas foram suficientes para levar a empreendedora ao êxito? Como elas se manifestam nos empreendimentos em geral?

\section{2- Leia com atenção e analise esse trecho:}

Antes de eles trabalharem na feira, faziam parte de um grupo de motociclistas, daquelas que passeavam pelas ruas, cujos membros (alguns deles) trabalhavam nos bancos 
da cidade. Um deles, percebendo o crescimento da barraca na feirinha, perguntou a D. Vera:

- A senhora não tem interesse num ponto melhor, já que está com a clientela desse grande porte na feirinha? Perguntou Carlos.

D. Vera, espantada, responde:

- Tenho sim, só que não tenho o dinheiro. Eu cheguei a ver algo aqui na avenida, mas está tudo muito caro, disse ela.

- A senhora tem coragem de construir? Perguntou Carlos.

- Tenho, disse ela, meu problema é que não tenho o dinheiro e nem o local.

- E se o banco tiver? Falou

Carlos. Prontamente, Vera

respondeu:

- Eu quero!!!!!!!

Frente a essa situação, o que você acha sobre a atitude de D. Vera ao aceitar prontamente a oferta de crédito bancário? Foi uma decisão acertada? O que você faria se estivesse no lugar dela? Você acredita que faltou, nesse momento, a característica empreendedora de planejamento e monitoramento sistemático? Justifique sua resposta.

Perguntas complementares:

1- A decisão de abandonar a empresa de cosméticos para se juntar ao esposo na agência de viagens foi acertada? Até que ponto correr riscos é saudável?

2- A falência da empresa de viagens do marido parece não ter afetado a perseverança da empresária a ponto de querer continuar a empreender. Qual a importância dessa característica empreendedora no contexto do caso de ensino? Contextualize com fatos descritos no texto.

3- O que se pode recomendar para novos empreendedores? Que lições podem ser extraídas, levando em conta as características empreendedoras e a situação apresentada?

4 Na sua concepção, existem desvantagens ao sair da empresa de cosméticos? Qual característica está intimamente ligada a essa decisão?

5- Qual a importância do Sr. Alberto dentro da história de D. Vera? Justifique com características empreendedoras ligadas a esse fato.

\section{Comportamento empreendedor na tomada de decisão}

Nessa etapa, o objetivo é que o aluno identifique os elementos na tomada de decisão no caso de ensino apresentado.

1- Simon (1970) sustenta que a decisão é um processo de análise e de escolha entre várias alternativas disponíveis no curso de ação que uma pessoa deverá seguir. Os elementos básicos que ele cita nesse processo são: tomador de decisão, objetivos, preferências, estratégia, situação e resultado. Após identificar no texto os fatos, associe e descreva os elementos;

2- A tomada de decisão causa impacto além do resultado imediato esperado. Visto que se espera uma decisão racional do empreendedor para obtenção de êxito, como você analisa, de forma geral, o processo da tomada de decisão da D. Vera?

3- Na sua concepção, os fatos anteriores ao início do empreendimento colaboraram de alguma forma para um incremento no comportamento empreendedor da direção da 
empresa? Justifique com trechos do caso de ensino.

\section{Possível organização da aula para uso do caso}

O professor dividirá a turma em dois grandes grupos, a partir da distribuição aleatória de pirulitos com duas cores distintas. Essa breve dinâmica incentiva a troca de conhecimento com pessoas diferentes dos círculos de amizade preexistentes na turma. Após finalizar a distribuição, pedirá aos alunos que se separem dentro da mesma sala, de acordo com a semelhança nas cores dos pirulitos, e distribuirá este caso de ensino para leitura naquele mesmo momento. É importante destacar que os principais textos das referências indicadas no final desta nota de ensino deverão ser lidos antecipadamente para facilitar a compreensão e associação de conteúdo. Assim, solicitará que eles discutam sobre características empreendedoras, comportamento empreendedor e tomada de decisão.

Os alunos resolverão as questões apresentadas neste instrumental e basearão suas respostas nas referências e no caso de ensino, além de apresentar o resultado ao final do tempo estabelecido para toda a turma.

O professor buscará associar os conceitos apresentados a este caso de ensino com outros exemplos da vivência dos alunos, promovendo a integração e discussão entre os grupos, ressaltando os fatores que caracterizam os conceitos propostos no presente caso, para que, ao se colocar no lugar dos empreendedores, tenham os conceitos reforçados.

É altamente recomendável também fazer uma compilação dos conceitos apresentados pelos alunos durante a discussão no quadro ou flip chart, para que fiquem visíveis a todos os alunos e, assim, cada grupo poderá ter os conceitos reforçados e atender aos objetivos pedagógicos do presente caso de ensino.

\section{Desfecho do caso}

Após o incidente e, com as sanções recebidas pela direção da feira, os empreendedores decidiram por fechar a barraca da feira de turismo e hoje tem somente um empreendimento na Orla de Aracaju. Depois de 10 anos, e com a empresa consolidada no mercado, atende em torno de sete mil clientes por mês, que consomem aproximadamente 14 mil pasteis, num cardápio de 30 sabores. Além dos pasteis, que respondem por $60 \%$ do faturamento do negócio, a empresa ampliou o cardápio com pratos típicos da região, muito procurados pelos turistas, e se tornou uma referência para quem quer conhecer melhor a culinária nordestina. Além de se diferenciar no cardápio, servindo tapiocas, caldos e outros pratos diferentes em uma pastelaria (SEBRAE, 2017).

\section{Referências}

Bressan, F., Toledo, G. L. A (2013, set-dez). Influência das Características Pessoais do Empreendedor nas Escolhas Estratégicas e no Processo de Tomada de Decisão. Revista Psicologia: Organizações e Trabalho, 13(3), pp . 309-324.

Dolabela, F. (1999). Oficina do Empreendedor: a metodologia de ensino que ajuda a transformar conhecimento em riqueza: $1^{\text {a }}$ ed. São Paulo: Editora Cultura, 1999. 
Préve, A.D, Moritz, G.O., Pereira, M.F. (2010). Organização, processos e tomada de decisão-Florianópolis : Departamento de Ciências da Administração / UFSC; [Brasília] : CAPES: UAB, 186p. : il.

Programa Bons Negócios (2015). Pastel da Jane. Recuperado em 21 de junho de 2018, de https://www.youtube.com/watch?v=BXoOZnbSaAw

Serviço Brasileiro de Apoio às Micro e Pequenas Empresas - SEBRAE (2017). Conheça as características empreendedoras desenvolvidas no Empretec. Recuperado em 5 de junho de 2018, de http://www.sebrae.com.br/sites/PortalSebrae/Programas/conheca-ascaracteristicas-empreendedoras-desenvolvidas-noempretec,d071a5d3902e2410VgnVCM100000b272010aRCRD

Saes, M. S. M., Martins, A. C. R., Schnaider, P. S. B. (2013, out./nov./dez.). Entrepreneurial decision-making using the knightian uncertainty approach. R.Adm., São Paulo, v.48, n.4, p.716-726.

Schumpeter, J. A. (1939). Business Cycles: A Theoretical, Historical and Statistical Analysis of the Capitalist Process. New York and London: McGraw-Hill Book.

Simon, H. A. (1970). Comportamento administrativo. Rio de Janeiro: FGV. 